\title{
Method for selective determination of polybrominated diphenylethers (BDE-47 and BDE-99) in landfill leachates by capillary gas chromatography and electron-capture detection
}

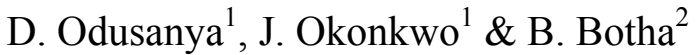 \\ ${ }^{1}$ Department of Environmental Science, \\ Tshwane University of Technology, Pretoria, South Africa \\ ${ }^{2}$ Department of Chemistry and Physics, \\ Tshwane University of Technology, Pretoria, South Africa
}

\begin{abstract}
The last few decades have seen dramatic growth in the scale of production and the use of polybrominated diphenylethers (PBDEs) as flame retardants. Consequently, PBDEs such as BDE-47, BDE-99, BDE-153 and BDE-209 have been detected in various environmental matrices. These compounds have also been linked with the disruption of the endocrine systems of man and wildlife. The present research work is aimed at determining the concentration of (PBDEs) in landfill leachates in Tshwane Municipality. A simulated landfill leachate was used to optimise various chromatograph parameters such as oven temperature programme, injector and detector temperature, carrier gas flow rate, and the limit of detection. A Varian GC coupled with ECD detector was used for the analysis. An effective method of recovery was developed using petroleum ether instead of hexane/acetone as reported by the literature. Recoveries of BDE-47 -99 and 209, each at a fortification level of $5 \mathrm{ng}$ and $6 \mathrm{ng}$ respectively, were in the range of $97.5 \%$ to $123 \%$ and relative standard deviation of 6 to $12(n=3)$. The method developed was applied to leachate samples collected from two landfill sites producing leachates (Temba and Soshanguve) in the Municipality. Results obtained are 0.90 and $0.13 \mathrm{mg} / 1$ for BDE-47 and 0.48 and $0.21 \mathrm{mg} / 1$ for BDE-99 respectively. BDE-209 was not detected. Compared to other studies these concentrations are significantly higher than those reported for Japanese landfill sites. Therefore, there is cause for concern if these leachates were to infiltrate into groundwater.
\end{abstract}

Keywords: flame-retardants, GC-ECD, landfill, leachates, PBDEs, waste. 


\section{Introduction}

The presence of persistent man-made chemicals in our environment has been a common problem since a large number of these chemicals have been identified in environmental samples. Apart from heavy metals, the group of chlorinated hydrocarbon pollutants that are regarded as major environmental problems include: polychlorinated biphenyls (PCBs), polychlorinated dibenzodioxins (PCDDs) and polychlorinated dibenzofurans (PCDFs). These chemicals are known to be harmful to man and the environment [1-7]. Their toxicity and presence in certain food items, mostly of animal origin, have resulted in the introduction of dietary restrictions and recommendations by food administrations in different countries $[2,3]$.

There are relatively new generation chemicals used in the industries as flame retardants called brominated flame retardants (BFR). Brominated flame retardants are chemical compounds that are added to polymers used in plastics, textiles, electronic circuitry and other materials to prevent fires [3]. Polybrominated diphenyl ethers (PBDEs) are important group of brominated flame retardants. PBDEs have been produced since 1970s and were first reported as environmental contaminants in River Viskan, in the early 1980s [8]. Since then, they have been found in most environmental matrices, including aquatic and terrestrial ecosystem [9-12,]. Recently, relatively high levels of PBDEs have been found in whales and dolphins stranded alive around the Dutch coast [13]. Studies have shown increased levels of PBDEs in environmental samples and human tissues, although the levels are still lower than those for PCBs and DDT $[14,15]$. There is little data available on the toxicology of the PBDEs flame retardants, the main findings published so far are changes in liver weight accompanied by historical alterations in animals given relatively large dose [15]. In humans, PBDEs like many halogenated organics, imbalance the level of the hormone thyroxin on exposure, consequently they have been classified as endocrine disrupting chemicals $[12,16,17]$.

Wastes from plastic, textile and other products with BFRs are either incinerated before being disposed into landfill sites or are disposed directly as they are with other municipal wastes. Since some BFRs such as PBDEs are additives that are not chemically bound to the plastic, it may be released more readily into the landfill environment. Bergman, [2] Meironyte-Guvenius and Noren [18] stressed that leaching is expected to be greater from additive flameretardants as compared to reactive flame-retardants. Studies on the leaching of PBDEs from landfill sites are scanty.

However, de Witt [19] and Oberg et al. [20] reported the distribution and levels of BFRs in sewage sludge of several treatment facilities in Sweden. In Minnesota, Oliaei et al. [21] surveyed the occurrence and concentrations of PBDEs (BDE-47, -99, -100, -153, -154, -207 and -208 in the leachate from five landfill sites with concentrations ranging from not detectable to thousands of pico-gram per litre. Masahiro et al. [16] reported the concentrations of BDE-47, -99 and -100 from seven different leachate samples to range from not detectable to $4000 \mathrm{pg} / \mathrm{l}$ for raw and treated leachate respectively. So far, there is still paucity 
of data on the presence of PBDEs in landfill leachates in developing countries including South Africa, where the environmental impact of PBDEs is yet to be determined.

The introduction of gas-liquid chromatography (GC) in 1952 [22] stimulated a rapid development of this technique. Over the years gas chromatography has firmly been established as a powerful and versatile method of analysis. Although, nowadays, gas chromatography-mass spectrometry (GC-MS) and gas chromatography-gas chromatography-mass spectrometry (GC-GC-MS) are the detection techniques generally used for the analysis of most halogenated compounds because they enable qualitative and qualitative analysis simultaneously, gas chromatography-electron capture detector (GC-ECD), is still used extensively for the same purpose because of its high specificity, sensitivity and resolution at very low concentration range [23-27]. Furthermore, the operation and maintenance of GC-ECD is a lot easier and cheaper than GC-MS and GC-GC-MS. Consequently, GC-ECD is very suitable for performing routine analysis, especially when the appropriate capillary column is used.

The present study was carried out using gas chromatography coupled with electron capture detector (GC/ECD), which is equally sensitive and efficient for environmental monitoring of organochlorine pesticides [4, 28]. Although most researchers have used hexane and acetone as extracting solvents this work presents the evaluation of efficiency of solvent extraction methods for common PBDEs (BDE-47, BDE-99 and BDE-209). The aim of this work was to validate an analytical method for the determination of PBDEs in landfill leachates from municipal landfills in Tshwane, South Africa.

\section{Materials/method of analysis}

\subsection{Reagents}

All the solvents used: hexane, dichloromethane (DCM), petroleum ether (PE), and acetone were of analytical grade. BDE-47, BDE-99 and BDE-209 standards were purchased from Industrial Analytical Pty. Ltd. South Africa and the rest of the PBDEs standards were donated by Dr. Jacob de Boer of Animal Sciences Group, Institute for Fisheries Research, Netherlands.

\subsection{Prepared simulated leachates}

2-liters of low and high concentration of leachates were prepared using deionised water according to USEPA standards [29].

\subsection{Determination of retention time, limit of detection, response factors and standard mixture}

From the stock solution, standards were prepared by serial dilution for individual standard as well as the mixture. $1.0 \mu \mathrm{l}$ of each standard at different concentrations was injected into the GC for necessary optimum output. The response factor (RF) of the PBDEs standards relative to the internal standard (I.S.), 
pentachloronitrobenzen (PCNB) were carried out by injecting $1.0 \mu$ of the appropriate mixture into the GC-ECD system. The response factor was calculated based on the equation below:

Response factor $=$ Peak area of the PBDEs standard/Peak area of the internal standard

For the determination of standard mixture, $1.0 \mu \mathrm{l}$ of standard mixture containing $250 \mathrm{ng} / \mathrm{ml}$ of BDE-47, 66.7ng/ml of BDE-99 and $33.3 \mathrm{ng} / \mathrm{ml}$ of internal standard was injected into the GC. These concentrations were selected based on the individual standard response to the GC conditions used.

\subsection{Liquid -liquid extraction (spiking)}

The validation of the LLE method was carried out by spiking simulated leachate with mixture of BDE-47 and BDE-99 at the fortification value of 100 and $120 \mathrm{ng} / \mathrm{ml}$ respectively, and then extracting with $3 \times 15 \mathrm{ml}$ of each of the extracting solvents (hexane, DCM, PE, and acetone). Petroleum ether/ acetone / hexane / (1:1:2) combination was also used. The extracts were dried with anhydrous sodium sulphate and concentrated to about $2 \mathrm{ml}$ using liquid nitrogen. Blank extraction of unspiked simulated leachate was carried out using the same solvents. The recoveries of the PBDEs congeners were first investigated in the low and high concentration of simulated leachates to check the effect of matrix on the extraction efficiencies. These recoveries were thereafter calculated.

Recoveries of the PBDEs standards were also investigated in raw leachate samples collected from Temba and Soshanguve landfill sites using the same PBDEs standards at the same fortification levels as for simulated leachates, to check the extraction efficiencies of the solvents on environmental samples.

\subsection{Silica gel column chromatography}

The extracts obtained were subjected to column chromatography by packing about $6.0 \mathrm{~g}$ slurry of silica gel to a column $(30 \mathrm{~cm} \times 8 \mathrm{~mm}$ I.D.). Before use the silica gel was activated overnight. Approximately $0.5 \mathrm{~cm}^{3}$ of anhydrous sodium sulphate was placed at the top of the column. The column was pre-eluted with another $10 \mathrm{ml}$ of the extracting solvent and just before the exposure of the anhydrous sodium sulphate layer to air, the reduced extract from the liquid-liquid extraction step above was placed in the column and allow to sink below the drying agent. The column was then eluted with $2 \times 15 \mathrm{ml}$ portions of the solvents under investigation. The combined elute of each of the solvent was collected into a $250 \mathrm{ml}$ RBF glass and anhydrous $\mathrm{NaSO}_{4}$ was added to remove water. After which nitrogen gas was bubble into the combined elute to concentrate it to about $2 \mathrm{ml}$ and anhydrous $\mathrm{NaSO}_{4}$ was added again before spiking with $0.5 \mathrm{ml}$ of $10 \mathrm{ng} / \mathrm{ml}$ of the internal standard (PCNB). $1.0 \mu 1$ of the extract was injected into the GC-ECD under the optimised instrumental condition.

\subsection{Capillary gas chromatographic analysis GC-ECD}

Separation and determination of the PBDEs congeners were carried out with: Varian CP-3800 Gas Chromatograph fitted with a CP-8400 Auto-sampler and 
equipped with $\mathrm{Ni}^{63}$ electron capture detector, with ZB-5 Capillary column, $5 \%$ phenyl and $95 \%$ dimethylpolysiloxane $(30 \mathrm{~m} \times 0.25 \mathrm{~mm}$ I.D. $x 0.25 \mu \mathrm{m})$ purchased from Phenomenex ${ }^{\circledR}$ (Separations) Randburg, South Africa. For data capturing star chromatography workstation version 6 was used.

The injector and detector temperatures were maintained at $250^{\circ} \mathrm{C}$ and $300^{\circ} \mathrm{C}$ respectively. The oven temperature was initially maintained at $90^{\circ} \mathrm{C}$ for $1 \mathrm{~min}$ and then programmed at $30^{\circ} \mathrm{C} / \mathrm{min}$ to $210^{\circ} \mathrm{C}$ and finally to $290^{\circ} \mathrm{C}$ at $10^{\circ} \mathrm{C} / \mathrm{min}$. The BOC gases, $99.99 \%$ ultra pure helium and nitrogen, purchased from Afrox (South Africa) were used as the carrier and make-up gases respectively. The carrier gas flow-rate was $3 \mathrm{ml} / \mathrm{min}$. while the make-up gas flow was set at $30 \mathrm{ml} / \mathrm{min}$ for optimum performance. $1.0 \mu \mathrm{l}$ of the standards and processed samples were injected into the GC in the split-less vent ratio of 40:1 after $2 \mathrm{mins}$ of injection for all analyses.

\subsection{Real leachate analysis}

To determine the profile of landfill leachates, samples were collected at two of the selected project sites namely: Temba, and Soshanguve landfill. An outline of the sites describing years of operation, site area and monthly classification of waste is shown below.

Table 1: Detailed description and general information on selected landfill sites.

\begin{tabular}{|c|c|c|c|c|c|c|c|}
\hline \multirow[t]{2}{*}{ Name } & \multirow{2}{*}{$\begin{array}{l}\mathrm{Ag} \\
\mathrm{e} \\
\mathrm{Yr} \\
\mathrm{s} .\end{array}$} & \multirow{2}{*}{$\begin{array}{l}\text { Site } \\
\text { Area } \\
\text { (Ha) }\end{array}$} & \multicolumn{5}{|c|}{$\begin{array}{l}\text { \% Monthly waste } \\
\text { Classification in Tonnage }\end{array}$} \\
\hline & & & Total & Building & $\begin{array}{l}\text { Garde } \\
\mathrm{n}\end{array}$ & Household & $\begin{array}{l}\text { Industria } \\
1\end{array}$ \\
\hline Temba & 10 & +3.7 & 9363 & 10 & 10 & 70 & 10 \\
\hline $\begin{array}{l}\text { Soshangu } \\
\text { ve }\end{array}$ & 10 & 19.5 & $\begin{array}{l}1220 \\
0\end{array}$ & 5 & 10 & 80 & 5 \\
\hline
\end{tabular}

Source: Adapted from daily/monthly reports of The Department of Solid Waste Management City of Tshwane 2005 [30].

\section{Results and discussion}

The gas chromatogram of the mixture of the PBDEs standard congeners plus the I.S. (pentachloronitrobenzen) is shown in Fig.1; the congeners were well resolved as shown below.

Table 2 shows the retention times, limit of detection and the response factors for the congeners. It was observed that the response of BDE-47 is higher than that of BDE-99 and no response for BDE-209.

Fig. 2 shows the chromatogram of a typical spiked simulated leachate. The efficiency of extraction of the PBDEs congeners from simulated leachates by LLE with hexane, DCM, PE and acetone in a $30 \mathrm{~m}$ ZB-5 column is presented in Table 3 below. From the result of the recovery analysis, the mean percentage recovery of PBDEs congeners with different extracting solvent ranged from 13.4 to $124.6 \%$. The high standard deviations obtained from the recovery analysis in Table 3 below may be due to matrix effect (high value of simulated leachate). 
Most of these solvents have been widely used in LLE of PBDEs congeners in environmental samples. The mean percentage recovery of BDE-47, -99 and -209 congeners with petroleum ether as extracting solvent gave the best result (97.5and $94.1 \%$ ) in low value simulated leachate with acceptable repeatability, followed by hexane/acetone (91.4 and 69.0\%). Hence, petroleum ether was used for LLE of PBDEs congeners in environmental samples. The optimum condition for LLE recoveries of PBDEs congeners from environmental samples could be obtained by introducing a cleanup procedure.

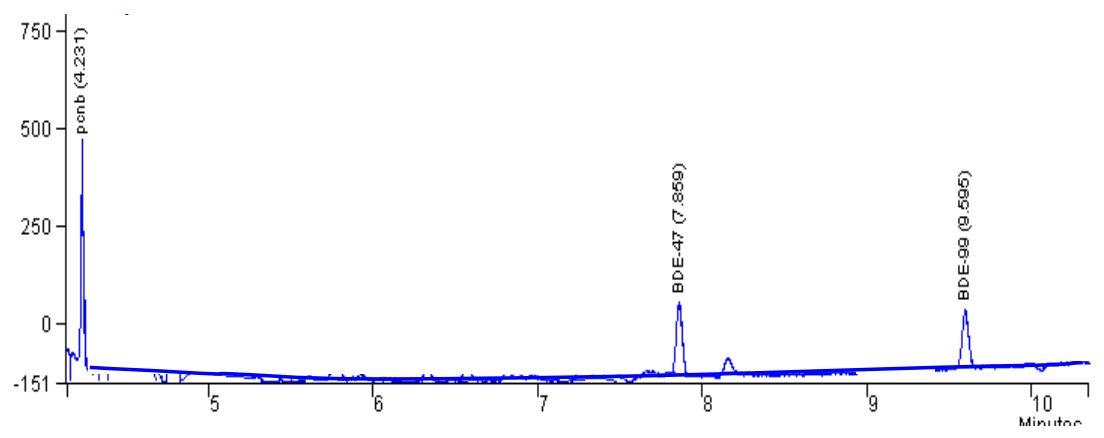

Figure 1: Chromatogram of $1 \mu \mathrm{l}$ of PBDE Mixture BDE-47 (7.85min), BDE99 (9.59min) and PCNB (4.23min) as internal standard.

Table 2: $\quad$ Retention time $\pm \mathrm{SD}$, limit of detection and response factor of PBDEs standards.

\begin{tabular}{|l|l|l|l|}
\hline Standards & $\begin{array}{l}\text { Retention time } \\
(\mathrm{min})\end{array}$ & LOD $(\mu \mathrm{g} / \mathrm{l})$ & Response factor \\
\hline BDE-47 & $7.867 \pm 0.03$ & 0.1 & $0.44 \pm 0.29$ \\
\hline BDE-99 & $9.596 \pm 0.44$ & 1 & $0.19 \pm 0.11$ \\
\hline BDE-209 & None & None & - \\
\hline PCNB & 4.234 & 0.01 & \\
\hline
\end{tabular}

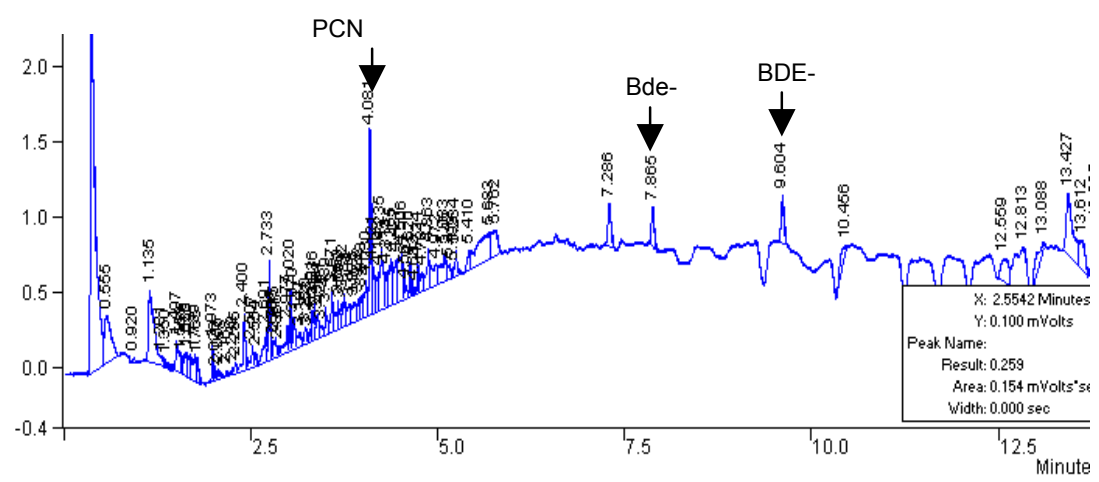

Figure 2: A typical chromatogram for spiked simulated leachate with BDE47 and BDE-99. 
Table 3: $\quad$ Mean percentage recoveries \pm S.D of PBDEs standards added to simulated leachates by LLE with different solvents.

\begin{tabular}{|l|l|l|l|l|}
\hline \multirow{2}{*}{ Extracting solvents } & \multicolumn{2}{|c|}{ BDE-47 } & \multicolumn{2}{c|}{ BDE-99 } \\
\cline { 2 - 5 } & \multicolumn{1}{|c|}{ LOW } & HIGH & LOW & HIGH \\
\hline Hexane & $63.7 \pm 12.9$ & $98.9 \pm 8.8$ & $91.7 \pm 27.6$ & $103.1 \pm 97.6$ \\
\hline Acetone & $23.8 \pm 13.9$ & $47.2 \pm 6.2$ & $87.9 \pm 88.0$ & $108.7 \pm 30.1$ \\
\hline Petroleum ether & $97.5 \pm 6.0$ & $123.6 \pm 12.1$ & $94.1 \pm 9.5$ & $117 \pm 7.4$ \\
\hline Dichloromethane & $63.7 \pm 14.3$ & $13.4 \pm 11.5$ & $124.6 \pm 21.8$ & $33.3 \pm 26.3$ \\
\hline Pet. Ether/DCM & $41.9 \pm 29.0$ & $96.6 \pm 26.1$ & $22.6 \pm 39.1$ & $66.2 \pm 64.3$ \\
\hline Pet. Ether/Acetone & $51.8 \pm 13.9$ & $22.5 \pm 3.4$ & $63.8 \pm 27.7$ & $37.8 \pm 7.3$ \\
\hline DCM/Acetone & $51.8 \pm 13.9$ & $22.5 \pm 3.4$ & $72.6 \pm 7.5$ & $37.2 \pm 7.4$ \\
\hline Hexane/Acetone & $91.4 \pm 17.9$ & $96.5 \pm 31.9$ & $69.0 \pm 60.0$ & $60.7 \pm 57.4$ \\
\hline
\end{tabular}

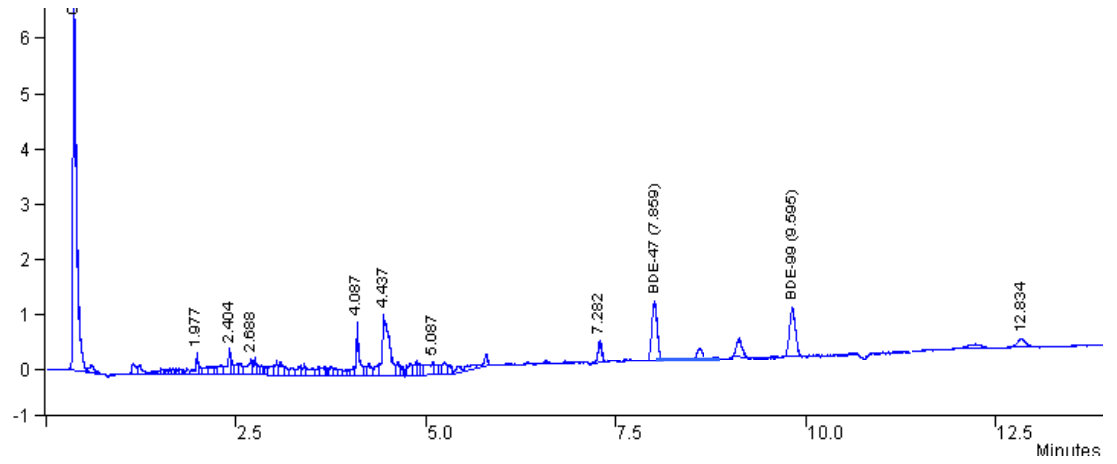

Figure 3: A typical chromatogram for raw leachate sample (Temba) with BDE-47 and BDE-99.

Table 4: $\quad$ The concentration (mg/l) of PBDEs (BDE-47,-99) in real leachates.

\begin{tabular}{|l|l|l|l|l|}
\hline \multirow{2}{*}{ PBDEs Congeners } & \multicolumn{2}{|l|}{ Temba raw leachate } & \multicolumn{2}{l|}{ Soshanguve raw leachate } \\
\cline { 2 - 5 } & BDE-47 & BDE-99 & BDE-47 & BDE-99 \\
\hline Concentration $\mathrm{mg} / \mathrm{l}$ & 0.90 & 0.13 & 0.48 & 0.21 \\
\hline
\end{tabular}

Fig. 3 is a typical chromatogram of raw leachate sample (Temba). The results of PBDEs levels in real leachates are presented in Table 4. The levels of BDE-47 and BDE-99 found in the leachates of Temba $(0.90$ and 0.13$) \mathrm{mg} / \mathrm{l}$ and Soshanguve $(0.48$ and 0.21$) \mathrm{mg} / \mathrm{l}$ are relatively higher than what has been reported in landfill leachates [16].

\section{Conclusion}

The present study shows LLE with petroleum ether as a good and reliable methodology of extracting BDE-47 and BDE-99 congeners from aqueous samples. An optimised methodology was developed, based on the injection of 
$1.0 \mu \mathrm{l}$ of the samples into $30 \mathrm{~m}$ ZB-5 column installed to a GC-ECD, in the splitless vent ratio of 40:1 after 2 mins of injection for all analyses. BDE-209 congener was not detected at all during this study. This may be due to its photo / biodegradation problems [22].

The validation parameter shows a satisfactory recovery of BDE-47 and BDE-99 for simulated leachate. The high levels of the PBDEs congeners detected in real leachate samples from these two sites, shows that landfill leachate may be contributing a significant amount of BFRs into the environment.

\section{References}

[1] Allchin, C. R., Law, R. J. and Morris, S. 1999. Polybrominated diphenylethers in sediments and biota downstream of potential sources in the UK, Environmental Pollution 105, p197-207

[2] Andersson O, Blomkvist G. 1981. Polybrominated aromatic pollutants found in fish in Sweden. Chemosphere 10(9):1051-1060.

[3] Bergman, A., 1989, 'Brominated fire-retardants in a global environmental perspective, in: proceedings Workshop on Aromatic Fire- retardants'. Skokloster, Sweden, pp.13-23

[4] Bras, I, Santos, L., Alves, A, 2000, Monitoring organochlorine pesticides from landfill leachates by gas chromatography- electron-capture detection after solid-phase microextraction, journal of chromatography A, $891 \mathrm{pp}$. 305-311

[5] Burreau S, Zeb HR, Ishaq R, et al. 2000. Comparison of biomagnification of PBDEs in food chains from the Baltic Sea and the North Atlantic Sea, Organohalogen Compounds 47:253-255.

[6] Darnerud, P. O. and Thuvander, A. 1998. Studies on immunological effects of polybrominated diphenyl ether (PBDE) and polychlorinated biphenyl (PCB) exposure in rats and mice, Organohalogen Compounds 35, $\mathrm{p} 415-418$

[7] Darnerud, P. O., Atuma, S., Aune, M., Cnattingius, S. and Wernroth, M.L. 1998. Polybrominated diphenyl ethers (PBDEs) in breast milk from primiparous women in Uppsala County, Sweden. Organohalogen Compounds 35, p411-414

[8] Darnerud, P., Gunnar, S., Torkell, J., Poul, B. \& Martti, V. 2001. Polybrominated Diphenyl Ethers: Occurrence, Dietary Exposure, and Toxicology, Environmental Health Perspectives Vol. 109, pp 49-67.

[9] de Boer J. 1989. Organochlorine compounds and bromodiphenylethers in livers of Atlantic cod (Gadus morhua) from the North Sea, 1977-1987. Chemosphere 18(11/12):2131-2140.

[10] de Boer, J., Wester, P. G., Pastor i Rodriguez, D., Lewis, W. E. and Boon, J. P. 1998. Polybrominated biphenyls and diphenylethers in sperm whales and other marine mammals- a new threat to ocean life, Organohalogen Compounds 35, p383-386 
[11] de Boer, J., Allchin, C.R., Law, R., Zegers, B.N., Boon, J.P., 2001. Method for the analysis of polybrominated diphenylethers in sediments and biota. Trends Anal. Chem pp 591-599.

[12] Eriksson, P., Jakobsson, E. and Fredriksson, A. 1998. Developmental neurotoxicity of brominated flame retardants, polybrominated diphenyl ethers and tetrabromo-bis-phenol A. Organohalogen Compounds 35, p375-377

[13] Fernlof G, Gadhasson I, Podra K, et al. 1997. Lack of effects of some individual polybrominated diphenyl ether (PBDE) and polychlorinated biphenyl congeners on human lymphocyte functions in vitro, Toxicol Lett 90(2-3):189-197.

[14] Hallgren, S. and Darnerud, P. O. 1998. Effects of polybrominated diphenyl ethers (PBDEs), polychlorinated biphenyls (PCBs) and chlorinated paraffins (CPs) on thyroid hormone levels and enzyme activities in rats, Organohalogen Compounds 35, p391-394

[15] Lindström, G., Wingfors, H., Dam, M. and Bavel, B. v. 1999. Identification of 19 polybrominated diphenyl ethers (PBDEs) in longfinned Pilot Whale (Globicephala melas) from the Atlantic. Archives of Environmental Contamination and Toxicology 36, p355-363

[16] Masahiro, O., Yong-Jin, K., Shin-ichi, S., 2004. Leaching of brominated flame retardants in leachates from landfills in Japan, Chemosphere 57, 1571-1579

[17] Meironyte-Guvenius DM, Noren K, Bergman A. 1999. Analysis of polybrominated diphenyl ethers in Swedish human milk. A time related trend study, 1972-1997. J Toxicol Environ Health A 58(6):329- 341.

[18] Meironyte-Guvenius DM, Noren K. 1999. Polybrominated diphenyl ethers in human liver and adipose tissues. A pilot study. Organohalogen Compounds 40:372-382.

[19] de Witt CA. 2002. An overview of brominated flame retardants in the environment. Chemosphere 46(5):583-624.

[20] Oberg K, Warman K, Oberg T. 2002. Distribution and levels of brominated flame retardants in sewage sludge. Chemosphere 48(8):805809.

[21] Oliaei F, King P, Phillips L. 2002. Occurrence and concentrations of polybrominated diphenyl (PBDEs) in Minnesota environment. Organohalogen Compounds 58:185-188.

[22] Sellström U, Soderstrom G, de Wit C, et al. 1998. Photolytic debromination of decabromodiphennyl ether (DeBDE). Organohalogen Compounds 35:447-450.

[23] Sjödin, A., Hagmar, L., Klasson-Wehler, E., Kronholm-Diab, K., Jakobsson, E. and Bergman, A. 1999. Flame retardant exposure: Polybrominated diphenylethers in blood from Swedish workers. Environmental Health Perspectives 107, p643-648.

[24] Troitzsch, J., H., 1999. Flammability and fire behaviour of TV sets Presented at the Sixth International Symposium of Fire Safety Science, 5 - 9 July, 1999 in Poitiers, France 
[25] Watanabe I, Tatsukawa R. 1987. Formation of brominated dibenzofurans from the photolysis of flame retardant decabromobiphenyl ether in hexane by UV and sunlight. Bull Environ Contam Toxicol 39:953-959.

[26] Watanabe I, Tatsukawa R. 1990. Anthropogenic aromatics in the Japanese environment. Workshop on brominated aromatic flame retardants, Skokloster, Sweden. KEMI, National Council Inspectorate, Solna, Sweden, 1990, 63-71.

[27] Watanabe I, Kashimoto T, Tatsukawa R. 1986. Confirmation of the presence of the flame retardant decabromiphenyl ether in river sediment from Osaka, Japan. Bull Environ Contam Toxicol 36(6):839-842.

[28] Yamamoto H, Okumura T, Nishikawa Y, et al. 1997. Determination of decabromodiphenyl ether in water and sediment samples by gas chromatograpy with electron capture detection. J AOAC Int 80(1):102106.

[29] U.S. Environmental Protection Agency (1996), Test Methods for Evaluating Solid Waste - Physical/Chemical Methods (SW-846), USEPA, Washington, DC.

[30] Daily/monthly reports of The Department of Solid Waste Management City of Tshwane 2005 